\title{
QUEEN'S
UNIVERSITY
BELFAST
}

\section{Young children's non-numerical ordering ability at the start of formal education longitudinally predicts their symbolic number skills and academic achievement in maths}

O'Connor, P., Morsanyi, K., \& McCormack, T. (2018). Young children's non-numerical ordering ability at the start of formal education longitudinally predicts their symbolic number skills and academic achievement in maths. Developmental science, 21(5), [e12645]. https://doi.org/10.1111/desc.12645

Published in:

Developmental science

Document Version:

Peer reviewed version

Queen's University Belfast - Research Portal:

Link to publication record in Queen's University Belfast Research Portal

Publisher rights

(c) 2017 John Wiley \& Sons Ltd.

This work is made available online in accordance with the publisher's policies. Please refer to any applicable terms of use of the publisher.

\section{General rights}

Copyright for the publications made accessible via the Queen's University Belfast Research Portal is retained by the author(s) and / or other copyright owners and it is a condition of accessing these publications that users recognise and abide by the legal requirements associated with these rights.

\section{Take down policy}

The Research Portal is Queen's institutional repository that provides access to Queen's research output. Every effort has been made to ensure that content in the Research Portal does not infringe any person's rights, or applicable UK laws. If you discover content in the

Research Portal that you believe breaches copyright or violates any law, please contact openaccess@qub.ac.uk. 
Running head: Ordinality and mathematical development

Young children's non-numerical ordering ability at the start of formal education longitudinally predicts their symbolic number skills and academic achievement in maths.

Patrick A. O’Connor, Kinga Morsanyi \& Teresa McCormack School of Psychology, Queen's University Belfast

Corresponding author: Patrick A. O’Connor

Queen's University Belfast, School of Psychology, David Keir Building Malone Road, Belfast, BT9 5AG. Tel: 02890976500 Email: poconnor08@qub.ac.uk

In press, Developmental Science

Accepted 19/10/17

Research highlights:

- Numerical and non-numerical ordering ability related to formal maths skills concurrently and longitudinally

- Non-numerical ordering abilities in the first year of school were the strongest predictors of maths one year later

- The study highlights the importance of domain-general ordering abilities to the early development of formal maths skills 


\begin{abstract}
Ordinality is a fundamental feature of numbers and recent studies have highlighted the role that number ordering abilities play in mathematical development (e.g., Lyons et al., 2014), as well as mature mathematical performance (e.g., Lyons \& Beilock, 2011). The current study tested the novel hypothesis that non-numerical ordering ability, as measured by the ordering of familiar sequences of events, also plays an important role in maths development. Ninety children were tested in their first school year and eighty-seven were followed up at the end of their second school year, to test the hypothesis that ordinal processing, including the ordering of non-numerical materials, would be related to their maths skills both cross-sectionally and longitudinally. The results confirmed this hypothesis. Ordinal processing measures were significantly related to maths both cross-sectionally and longitudinally, and children's nonnumerical ordering ability in their first year of school (as measured by order judgments for everyday events and the parents' report of their child's everyday ordering ability) was the strongest longitudinal predictor of maths one year later, when compared to several measures that are traditionally considered to be important predictors of early maths development. Children's everyday ordering ability, as reported by parents, also significantly predicted growth in formal maths ability between Year 1 and Year 2, although this was not the case for the event ordering task. The present study provides strong evidence that domain-general ordering abilities play an important role in the development of children's maths skills at the beginning of formal education.
\end{abstract}

Key Words: Longitudinal Design; Magnitude Processing; Mathematics Development; Mental Number Line; Order Processing 
The relations between order processing abilities and the development of maths skills has recently attracted the interest of researchers. Lyons and Beilock (2011) proposed that representing and processing the relative order of numbers is a stepping stone in moving from approximate representations of number to exact representations. Separately, other researchers (e.g., Attout, Noël, \& Majerus, 2014; Attout \& Majerus, 2015) have proposed that working memory for order information is important for early mathematics development.

Ordinality is a fundamental aspect of the symbolic number system, referring to the position in which a numeral is found within the number sequence. One proposal is that performance in tasks that tap children's ability to process symbolic order reflects the extent to which they have a refined spatialized representation of the number sequence along a mental number line (Kaufman, Vogel, Starke, Kremser, \& Schocke, 2009). However, this suggestion does not explain why performance on non-numerical working memory tasks, which involve temporarily holding short non-numerical sequences in short-term memory, is related to maths abilities (Attout et al., 2014; Attout \& Majerus, 2015). Existing findings suggest that the representation of the ordered number sequence in long-term memory and the ability to hold and process unfamiliar order information in short-term memory are both important for maths.

We believe that ordering skills and mathematics might be related for multiple reasons. Most relevant to young children is the fact that learning to count involves learning an ordered sequence of items. Additionally, even the simplest counting principles (Gelman \& Gallistel, 1978), such as the stable order principle (i.e., numerals always have the same order in a count), and the cardinal principle (i.e., the numeral applied to the last item in a set, represents the number of items in the set) involve reference to ordinality. Nieder and Dehaene (2009) argue that it is difficult to envisage how children could acquire knowledge of the symbolic number system, beyond rote learning or other compensatory strategies, if they did not understand the correct order in which the numbers are arranged. Successful arithmetic 
performance is dependent upon both knowledge of the correct order of the numbers, and an understanding of the correct order in which mathematical operations should be carried out. For example, if children are asked to solve the problem "5-2=?", to arrive at the correct solution they must understand that they should take 2 away from 5 , rather than vice versa. Thus, calculation itself depends upon temporarily holding order information in working memory. Processing order information is also essential for working with multi-digit numbers. It can be argued, therefore, that mental representations of order may play a role in the development of both basic symbolic number knowledge and subsequent maths ability, and recent evidence suggests that there is indeed a relationship between the processing of numerical order relations and maths achievement in both children and adults.

The most widely used task to assess symbolic ordering ability is the ordinal judgment task (e.g., Goffin \& Ansari, 2016; Lyons \& Beilock, 2011). Participants are shown three numbers on the screen (half of the pairs or triads are in the correct order, the other half are in incorrect order) and they must judge whether the numbers are in the correct ascending order, from left to right. A task developed to assess non-numerical order processing skills is the order working memory (WM) task (e.g., Attout \& Majerus, 2015). In this task, participants hear lists of familiar animal names. The lists range from 2-7 animals in length, and participants must re-create the correct sequence of animals using cards that represent the animals in the list that they have just heard. Importantly, the cards given to participants inform them about both the identity and the number of animals within the list. Thus, the task makes minimal demands on item memory; participants must only remember the order of items. As will now be described, several studies have indicated that performance on both these types of order processing tasks is linked to maths ability, suggesting that both numerical and non-numerical ordering ability may be important for formal maths skills. 
In a large study of children across grades 1-6 of school, Lyons et al. (2014) investigated the role of basic number skills in the development of maths ability. The authors used a wide range of numerical and non-numerical tasks to investigate what skills were important for maths at different developmental stages. They found that the predictive power of numerical ordering ability (i.e. the ordinal judgment task) increased across grades. At the earliest grades, numerical ordering was not a strong predictor of maths, but by grade 6 (around the age of 12), it was the strongest of all the predictors. Another paper (Vogel, Remark, \& Ansari, 2015) reported no relationship between distance effects in number ordering and first-graders' (around age 6-7) mathematics performance. However, Vogel et al.'s ordering task only contained dyads of numbers, rather than the triads that are more commonly used in this literature, and it is possible that the dyad task is less sensitive at detecting the appropriate order processing skills (though see Attout \& Majerus, 2015). Overall, these studies suggest that symbolic ordering ability is important to children's maths skills, although the strength of this relationship might change with development.

Attout et al. (2014) investigated the links between verbal WM abilities (nonnumerical item and order WM), numerical magnitude and order processing abilities and calculation performance at three different time points: 6 months into the final year of kindergarten (T1), one year later (T2) and during the second grade of school (T3). Attout et al. found that the only relationship between children's numerical ordinal judgement and maths was observed cross-sectionally at T2. On the other hand, children's performance in the order WM task was cross-sectionally related to maths at each time point, whilst performance on this task at T1 was longitudinally related to maths at T2 and T3, suggesting the importance of early non-numerical order memory to later maths performance. These relationships remained significant, even after controlling for age, verbal and non-verbal intelligence. 
A relationship between order processing and maths has been found not only in studies involving typically developing children, but also in studies involving children with developmental dyscalculia (DD); a developmental disorder characterized by difficulties in the retrieval and storage of arithmetic facts, when no other sensory or intellectual disabilities are present (e.g., Butterworth, 2005; von Aster \& Shalev, 2001). Attout and Majerus (2015) investigated symbolic and non-symbolic magnitude and order processing in 8 to 12 -year-old children with DD and a group of typically developing children matched on age, IQ and reading abilities. The children were given the order working memory task, as well as a calculation task, symbolic and non-symbolic ordinal judgment tasks (judging whether two sets of lines or numerals were in the correct ascending order numerically) and symbolic and non-symbolic magnitude judgment tasks (judging which of two sets of lines or numerals were the most numerous). Attout and Majerus found that the DD group tended to be slower on symbolic magnitude and ordering tasks and committed more recall errors in the order working memory task, suggesting that children with DD may have difficulties in processing and remembering order information.

Together, the evidence suggests that both numerical and non-numerical ordering abilities are important to the development of typical maths skills, and that children with DD have order processing deficits. Whilst the evidence is promising, there are still several important unresolved issues concerning the link between order processing skills and maths. In particular, we do not know the precise nature of the order processing skills that are important for maths development. Two quite distinct types of order processing tasks - the numerical ordinal judgment task and the order working memory task - have each shown a link with children's mathematical skills. Notably, Attout et al. (2014) found that children's performance on these two types of ordering tasks was not correlated (though see Attout \& Majerus, 2015); performance on the tasks also showed quite different patterns of cross- 
sectional and longitudinal relations with maths skills. This suggests that they draw on different order processing skills and are related to maths skills for different reasons. Indeed, these tasks differ in two salient respects: (i) in terms of whether they involve processing of numerical or non-numerical order information and (ii) in terms of whether they involve retrieving and processing information from order representations held in long-term memory versus unfamiliar sequences temporarily held in short-term memory. Attout et al. (p. 1676) suggest that "order WM abilities predict calculation abilities not via access to a common set of (long-term) ordinal representations but via mechanisms intrinsically associated with shortterm storage capacities of order information." What is not clear is whether such short-term memory mechanisms are the only domain-general order processing ones that are important for maths development, because previous studies with children have not used tasks involving long-term ordinal representations of non-numerical information.

Lyons, Vogel, and Ansari (2016), in their review of the literature examining the links between ordinality and mathematical skills, argue that there is a paucity of research investigating the relation between non-numerical ordering abilities and maths. Recent studies with adults (Morsanyi, O’Mahony, \& McCormack, 2017; Sasanguie, Lyons, De Smedt \& Reynvoet, 2017; Vos, Sasanguie, Gevers \& Reynvoet, 2017) showed that non-numerical order processing, as measured by month and letter ordering tasks that required participants to make judgments about the order of month/letter triads, was very strongly related to adults' numerical skills, and the distance effects found in these tasks were also similar to the distance effects found in number ordering tasks. Thus, the ordering of familiar non-numerical sequences is also related to maths ability, at least in adults. In order to investigate this issue developmentally, in the current study we included tasks that measured ordering ability involving familiar, non-numerical sequences. 
We investigated the ability to process order information regarding familiar nonnumerical sequences held in long-term memory by introducing two measures that have not been used previously. First, a temporal ordering task, inspired by previous research with young children (Friedman, 1977, 1990) was employed. The version of the task that we developed is similar to the number ordering tasks used in other studies (e.g., Lyons \& Beilock, 2011; Lyons et al., 2014), except that children were shown a pictorial representation of a triad of daily events rather than numbers. Each test trial was drawn from a set of six events (waking up, getting dressed, going to school, eating lunch, eating dinner and going to bed) and children judged whether the order of the events was correct or not. Second, to assess the role of everyday non-numerical ordering skills, we developed a new eight-item questionnaire to assess the extent to which parents agreed or disagreed that their child could carry out familiar tasks that all included a requirement to follow a set order (such as getting dressed for school). Our motivation for using this measure was the existence of clinical reports of individuals with DD that describe how they often struggle with everyday tasks that have a strong ordering component (National Center for Learning Disabilities, 2007).

Together, these tasks provided us with a novel way of assessing the relation between domaingeneral order processing abilities and emerging maths skills.

In addition to the question of what types of order processing skills are related to maths at the start of formal education, it is also of concern that there is a lack of longitudinal research investigating whether there may be a causal relationship between ordering ability and the early development of maths skills. This is echoed by Lyons et al. (2016), who point out that most of the findings concerning the link between ordering abilities and maths have been based on correlational evidence at a single time point. The only longitudinal study so far was conducted by Attout et al. (2014) who found separate cross-sectional links between both numerical ordering and non-numerical order working memory and maths, but only a 
longitudinal link between order working memory and maths. We employed a longitudinal design that involved children completing a range of tasks at the very start of their formal education, and then measuring their formal maths skills towards the end of their first and second year of school.

We studied children in their earliest years of education to address a further issue arising from the previous literature concerning the stage of development at which ordering ability becomes an important predictor of maths skills. Studies (e.g. Attout \& Majerus, 2015; Lyons et al., 2014; Morsanyi et al., 2013) have consistently shown that order processing is strongly related to maths skills amongst older children (between the ages of 8-13). However, as mentioned above, there are mixed finding regarding whether there is a strong link between ordering abilities and maths at the start of formal education (Attout et al., 2014; Lyons et al., 2014; Vogel et al., 2015), with Lyons et al. (2014) finding that this relation only becomes pronounced with development. The children in the current study were between the ages of 45 when they first participated in the study, which makes them the youngest sample so far in which the link between order processing skills and maths ability has been investigated. It was conducted with a sample of children from Northern Ireland; Northern Ireland has the youngest school starting age (4 years old) of all the 37 countries participating in Eurydice, the information network on education in Europe (Eurydice at NFER, 2012), and one of the youngest school starting ages in the world.

Finally, it is also important to compare the predictive value of ordering tasks with other tasks that are related to mathematical skills (see e.g., Attout et al., 2014; Lyons et al., 2014; Vogel et al. 2015). Given the amount of research interest in whether the ability to process magnitudes is related to maths (e.g. Chen \& Li, 2014; Gilmore, McCarthy \& Spelke, 2010; Halberda, Mazzocco \& Feigenson, 2008; Holloway \& Ansari, 2009; Piazza et al., 
2010; Schneider et al., 2014), the current study included both symbolic and non-symbolic magnitude measures.

In sum, the aim of the current study was to assess the relative contributions of numerical and non-numerical order processing to the development of maths skills in children, who have just begun formal maths instruction. In a longitudinal study, children were tested during their first year of primary school and completed a maths assessment at the end of the school year. The same children completed another maths assessment at the end of their second year of primary school. The main research question concerned whether numerical and non-numerical ordering abilities predicted variance in mathematical skills both crosssectionally and longitudinally, after other powerful predictors of early mathematical skills, as well as children's verbal and non-verbal intelligence, were taken into account. Additionally, the current study was the first to investigate the link between non-numerical ordering tasks including familiar and everyday sequences and maths performance at the start of formal education.

\section{Method}

\section{Participants}

Ninety children at the start of their first year of primary school education were recruited from four schools in the Belfast area (43 females, Mean age $=4$ years 11 months; $S D=3.73$ months). Eighty-seven children completed the maths assessment (43 females, Mean age $=6$ years 2 months, $S D=3.44$ months) at the end of their second school year. Due to the demographics of the population in Northern Ireland, the vast majority of children were of Caucasian origin; information on their SES is reported below.

\section{Materials}

Deprivation measure. Children's level of socio-economic deprivation was determined using the Northern Ireland Multiple Deprivation Measure (Northern Ireland 
Statistics and Research Agency, 2010). This measure assigns a deprivation score to each electoral ward in Northern Ireland based on a variety of indices. A higher score indicates a higher level of deprivation for the area. The scores can be interpreted as percentiles (e.g., a score of 10 means that the area is less deprived than $90 \%$ of all postcode-based areas within Northern Ireland). In the current sample, deprivation scores ranged from $1.85-68.57$ $($ Median $=11.00)$. One child did not provide a postcode, so a deprivation score could not be calculated. Along with age and both verbal and non-verbal intelligence, children's deprivation scores were used as covariates in the data analysis.

IQ. Children's intelligence was measured using the Vocabulary and Block Design subtests of the Wechsler Preschool \& Primary Scale of Intelligence - Third UK Edition (WPPSI-III UK; Wechsler, 2003). Children's estimated full-scale IQ scores were computed following the method outlined in Sattler and Dumont (2004) and were found to be within the normal range $($ Mean IQ score $=95.92, S D=13.51)$.

\section{Order processing measures.}

Parental Order Processing Questionnaire (OPQ). Parents were asked to complete an eight-item questionnaire (included in the Appendix) in which they indicated on a 7-point Likert scale the extent to which they agreed or disagreed with certain statements regarding their child's ability to perform everyday tasks that involved an order processing element (e.g., "my son/daughter can easily recall the order in which past events happened"). The items were developed based on clinical observations regarding the everyday difficulties that individuals with dyscalculia commonly encounter (National Center for Learning Disabilities, 2007), but they were modified to be appropriate for young children. Five items were scored positively (i.e., higher scores indicated better ordering ability), and 3 items were scored negatively. A principal component analysis with varimax rotation showed that the scale had a 2-factor structure, with the positive items loading on factor 1 (which explained $41 \%$ of the variance), 
and the negative items loading on factor 2 (which explained $21 \%$ of the variance). The scale demonstrated good internal consistency (Cronbach's alpha $=.75)$. The total score from this scale was used as a measure of children's ability to carry out everyday tasks requiring a longterm memory representation of the correct order of sequences. Five parents did not complete the questionnaire, so no score could be computed on this measure for their children.

Order Working Memory (WM) task. This task measured children's ability to retain serial order information. The English version was modelled on a task developed by Majerus and colleagues (Attout \& Majerus, 2015; Attout, Noël \& Majerus, 2014; Majerus, Poncelet, Greffe \& Van der Linden, 2006). This task measures children's ability to retain and manipulate serial order information by measuring their ability to recreate the correct sequence of a list of animal names that were presented to them through a set of earphones, using cards depicting the animals. The stimuli used were seven monosyllabic English animal words (bear, bird, cat, dog, fish, horse, and sheep). The mean lexical frequencies of these words were established using SUBTLEX-UK word frequencies (SUBTLEX-UK: Van Heuven, Mandera, Keuleers \& Brysbaert, 2014). SUBTLEX-UK presents word frequencies as Zipf values, with values between 1 and 3 representing low frequency words and values between 4 and 7 representing high frequency words. The stimuli demonstrated high lexical frequency according to these values (mean lexical frequency $=4.94$, range $=4.67-5.19$ ). The stimuli were used to create 24 word lists, which ranged in length from two to seven words, with four trials per list length. Each word only appeared once per list and the same 24 lists were presented to all participants. The stimuli were recorded by a female voice, an inter-stimulus interval of $650 \mathrm{~ms}$ was used. Mean item duration was $565 \mathrm{~ms}$ (range $=407-674 \mathrm{~ms}$ ). For each correctly recalled sequence, children were given a score of 1 . Split-half reliability estimates, using the Spearman-Brown formula, indicated good reliability $(r=.93)$. 
Daily Events task. A modified version of Friedman's (1990) temporal ordering task was used to measure children's ability to judge the correctness of the order of familiar daily events. Children were first trained on how to order events using two training sequences (four cards showing a boy playing on a slide, and six cards depicting a sequence in which a boy picked up and opened a present). Children had to correctly order both sequences four times, before they could proceed to the next phase of the training, which involved the items of the experimental sequence. The experimental sequence consisted of six cards that represented six familiar events that happen during the day (waking up, getting dressed, going to school, eating lunch, eating dinner and going to bed). For the training phase, children were first told what each picture represented and were shown the correct order by the experimenter. Then the cards were shuffled and children were asked to recreate the correct order. For the experimental sequence, children learned the names for each of the daily events and saw the correct order in which these events should go. After this, children were given a computerbased task in which they were told that they would see any three of the daily events and that their task was to judge whether the order was correct or not, from right to left, by pressing a tick or a cross on the touchscreen monitor. Half of the 24 trials (there were 12 sets that were presented twice) showed a triad of events in the correct order, the other half showed a triad that was in the incorrect order. Children were given a score of 1 for each correct answer and a measure of children's reaction times, for correct trials only, was also taken. Since each trial was presented twice, a split-half reliability was calculated using the Spearman-Brown coefficient, which was found to be adequate (.57). Due to the relatively high error rate, reliability for RTs for correct trials was not computed, and the RT measure was not considered further. 
Symbolic number ordering ${ }^{1}$. This task assessed children's early knowledge of the order of symbolic numbers. Children were shown the correct sequence of the numbers 1-9 using cards. These cards were then shuffled and children were asked to recreate the correct forward order (involving two trials). This procedure was then repeated for the backward sequence of numbers (two trials). In two subtasks, children also ordered the numbers forwards (4 trials) and backwards (4 trials) from different starting positions, with a score of 1 given for each correct trial. The proportion of correct responses was calculated based on performance on all 4 of the ordering tasks. A reliability estimate for the total score was high $($ Cronbach's alpha $=.93)$.

Counting. This task was based on the number sequence elaboration task, as outlined in Hannula and Lehtinen (2005). In the first part, children were asked to count from 1 until the highest number they could think of (they were stopped if they reached 50) in two trials. In two further subtasks, children also counted forwards and backwards from different starting points. Children could correct themselves once during any trial. The reliability estimate for both forward and backward subtasks combined was good (Cronbach's alpha $=.77)$.

Given the strong correlation between counting until the highest number and both forward $(r(88)=.76, p<.001)$ and backward counting $(r(88)=.65, p<.001)$, a total counting score was calculated by adding z-scores for all 3 counting measures.

\section{Magnitude processing measures.}

\footnotetext{
${ }^{1}$ The typical task in the literature that is used to measure number ordering ability is a computer-based task in which children are shown dyads or triads of numbers and have to judge whether the order is correct or incorrect/ascending or descending. We piloted a computer-based number ordering task with children from this age group using triads (i.e., comparable to our daily events ordering task) and found that they struggled to perform the task, even after a short training that was provided using cards representing the numbers. By contrast, they were able to complete the computer-based version of the daily events task, after a training session with cards representing the events.
} 
Non-symbolic Addition ${ }^{2}$. This task measured the ability to represent and manipulate non-symbolic quantities and was based on the procedure used by Gilmore, McCarthy and Spelke (2010), in which children view two sets of blue dots or 'marbles' that a character had, which appear one after the other on the left-hand side of the screen, and have to estimate the sum of the two arrays (sum array) and compare that sum to the quantity of a third array (comparison array, composed of red dots) that a different character had, which appeared on the right-hand side of the screen. The numerical ratio of the sum and comparison arrays was manipulated across the 24 trials (1:2, 3:5, and 2:3), with 8 trials per ratio. The number of dots for both arrays varied from 6 to 45; 6 being the lowest number of dots as this reduced the possibility that children could subitize the number of dots presented. Perceptual variables (dot size, density and array size) were also varied, so that they correlated with numerosity on half the trials (congruent trials) and were uncorrelated on the other half of the trials (incongruent trials), reducing the possibility that children may have used perceptual information as a cue when judging which array was the most numerous. Furthermore, the trials were designed in a way so that it was not possible for the children to perform above chance if they simply responded on the basis of a comparison between the number of blue dots in the second set and the number of red dots. In each trial the number of red dots was at least 1.5 times greater than the number of blue dots in the second set. Nevertheless, the overall number of blue dots

\footnotetext{
${ }^{2}$ We selected this task, rather than non-symbolic comparison, due to the inconsistency of the evidence supporting a link between non-symbolic comparison and maths in developmental studies (De Smedt, Noël, Gilmore \& Ansari, 2013), which may be, in part, due to a lack of an agreed measurement of task performance used in these studies (e.g., Inglis \& Gilmore, 2014; Price, Palmer, Battista \& Ansari, 2012). In contrast, the non-symbolic addition task has been found to be a longitudinal predictor of maths achievement, as well as being related to mastery of both number words and symbols, which underlies much of early maths learning (Gilmore, McCarthy \& Spelke, 2010). Furthermore, other evidence (Gilmore, Attridge, De Smedt \& Inglis, 2014; Iuculano, Tang, Hall \& Butterworth, 2008) has showed that performance on non-symbolic addition and comparison tasks are correlated, suggesting that both tasks are measuring the same underlying construct, whereas non-symbolic comparison performance has been found to be unrelated to symbolic comparison performance (e.g. Sasanguie, Defever, Maertens \& Reynvoet, 2014).
} 
was larger in half of the trials than the overall number of red dots, whereas in the other half of trials the opposite was true. In the task, children had to press one of two buttons on the touchscreen to indicate which character they thought had the most marbles. They completed four practice trials, with feedback given on their performance, followed by 24 experimental trials. Children were given a score of 1 if they correctly judged which character had the most marbles. Reliability for this task for accuracy was quite low, but acceptable (Cronbach's alpha $=.50)$. However, one-sample $t$-tests confirmed that children performed above chance at each ratio $[1: 2 ; t(89)=4.45, p<.001 .3: 5 ; t(89)=3.76, p<.001 .2: 3 t(89)=2.93, p<$ $.001]$.

Number Comparison. Children's ability to compare symbolic quantities was assessed using a computer-based Number Comparison task (e.g., Dehaene, Dupoux, \& Mehler, 1990) in which children were presented with a target number (between 1-4 or 6-9) and were asked to press one of two buttons to indicate whether they thought that the number on the screen was bigger or smaller than 5. Each number was presented five times, in a random order, giving a total of 40 experimental trials. These were preceded by 4 practice trials. Children were scored 1 for each trial in which they correctly judged whether the target number was bigger or smaller than 5 , with reaction time data also obtained. Reliability estimates for accuracy $($ Cronbach's Alpha $=.88)$ and reaction times $($ Cronbach's Alpha $=.66)$ were good.

\section{Estimation measure.}

Number Line task. The number line task (Cohen \& Blanc-Goldhammer, 2011; Laski \& Siegler, 2007, Link, Huber, Nuerk \& Moeller, 2014; Siegler \& Opfer, 2003) was used to assess children's ability to spatially represent numbers along a mental number line. This task used the number-to-position version, in which children used their finger to indicate the position on the number line where a target number should go. This version used 1-10 and 120 scales, and it was framed as a game in which the children had to help Postman Pat to 
deliver presents to houses on different streets (Aagten-Murphy et al., 2015). There were six experimental trials, in which the child was asked to indicate the position of numbers $3,4,6$, 7, 8 and 9 . For the 1-10 number line, the numbers 5 and 10 were used as the two practice trials; for the 1-20 number line, the numbers 10 and 20 were used as the two practice trials, whilst the child was asked to indicate the position of the numbers $4,6,8,13,15$ and 18 in the six experimental trials, which were presented in a random order. Children's error for each individual trial was calculated as the distance in pixels between children's estimated position and the actual position of the target number. The average of children's errors across both 1-10 and 1-20 scales was used as the overall measure of estimation error for the task. A reliability estimate was computed (Cronbach's alpha $=.70)$.

Maths Achievement. At the end of their first year of school, children's maths ability was assessed by administering a 28-item maths achievement test, consisting of questions from the calculation subtest of the Woodcock-Johnson III tests of achievement (Woodcock, McGrew \& Mather, 2001) and from Form A of the Test of Early Mathematics Ability (TEMA-3; Ginsburg \& Baroody, 2003). The questions from the calculation subtest contained 6 addition and 4 subtraction problems, whilst the questions from the TEMA-3 included the counting of objects and animals, selecting the next number after a given number in the counting list, as well as selecting which number is larger from a choice of two. At the end of their second year of school, children were assessed using the age-appropriate version of the Maths Assessment for Learning and Teaching (MALT; Williams, 2005) which consisted of 30 questions, assessing counting and understanding number (9 questions), knowing and using number facts (7 questions), calculating (8 questions) and measuring (6 questions). Children's raw scores on both maths measures were used in the analyses. The reliability estimates for the maths measure at the end of children's first year of school (Cronbach's alpha $=.91)$ and for the MALT at the end of children's second year (Cronbach's alpha $=.83$ ) were high. 


\section{Procedure}

The study received ethical approval from the university department's ethics committee. In Session 1, all children completed the Number Ordering task, followed by the Number Comparison task, the Animal Race task and finally, the Non-Symbolic Addition task. In Session 2, children completed the Daily Events Order Task, followed by the WPPSIIII subtests, then the Baseline Reaction Time Task, Counting task and then finally, the Number Line task. The computer-based tasks were designed using E-Prime Version 2.0. These tasks were presented on a touch screen, connected to a laptop. At the end of each school year (Time $1=$ end of year 1 ; Time 2 = end of year 2 ), children completed the maths achievement test in small groups of 3-6, in which the experimenter read out the questions and instructed the children to write down their answers. All other tasks were administered individually.

\section{Results}

Descriptive statistics for both accuracy and reaction times are included in Table 1. The median number that children were able to count up to (out of 50) was 39. Most children performed well on the two numerical ordering tasks (forward and backward counting mean accuracy $=76 \%)$ and on number ordering $(82 \%)$. Two children performed very poorly in these. In the non-numerical ordering tasks, children did not perform quite as well. In the daily events task, children's accuracy was $65 \%$, which was above chance $(t(89)=11.10, p<$ $.001)$. In the order working memory task, children on average got 11 trials correct, meaning that they were able to correctly remember ordered sequences to a sequence length of 4 . Children's mean score on the OPQ was 44.02 out of 56, with parents tending to rate their 
children highly in terms of being able to carry out everyday tasks with a strong ordering component.

As previously mentioned, children's accuracy on the non-symbolic addition task was relatively low, but their performance on the task was above chance $(t(89)=5.09, p<.001)$. Children performed much better on the number comparison task. In the number line task, children's estimates on the 1-10 scale were on average about 1.8 numbers away from the target number, whilst their estimates on the 1-20 number line were on average about 3.4 numbers from the target.

[INSERT TABLE 1 HERE]

\section{Zero-order and partial correlations (after controlling for age, IQ and socio-economic status) between the order and magnitude processing measures, counting ability and maths achievement at the end of children's first year of school}

Table 2 shows that vocabulary scores were significantly positively correlated with order-processing (order WM, daily events, counting) and non-symbolic addition and maths scores. Block design scores were significantly positively correlated with the order-processing measures (order WM, daily events, number ordering), as well as performance on the number line task. Finally, higher deprivation scores were significantly related to lower performance on both IQ measures and maths, as well as lower performance on the order WM, daily events, number ordering and number comparison tasks.

As shown in Table 2, there were significant correlations between general orderprocessing measures and maths at the end of children's first year of school; children's maths ability was related to their scores on the OPQ, number ordering ability, daily events task accuracy, counting ability and their order working memory accuracy. Of the magnitude measures, only number comparison was found to be related to maths. After controlling for age, deprivation scores and verbal and nonverbal intelligence, number comparison 
performance was no longer significantly related to maths performance $(p=.29)$. OPQ scores $r(78)=.26, p<.05$; number ordering performance, $r(78)=.25, p<.05$; daily events accuracy, $r(78)=.36, p<.01$; counting ability, $r(78)=.43, p<.001$; and order WM accuracy, $r(78)=.30, p<.01$, remained significantly related to maths after controlling for the covariate measures.

\section{Zero-order and partial correlations between the order and magnitude processing measures, counting and maths achievement at the end of children's second year of school}

Table 2 shows that vocabulary, block design and deprivation scores at T1 were significantly related to maths at T2. Children's T1 OPQ scores, daily events task accuracy, number ordering ability, order working memory accuracy, daily events accuracy and counting ability were related to maths ability at the end of children's second year of school. For the magnitude measures, both non-symbolic addition accuracy and number comparison accuracy were related to maths. After controlling for age, deprivation scores and verbal and non-verbal intelligence, the only significant relationships with maths were observed for OPQ scores, $r(75)=.24, p<.05$; counting ability, $r(75)=.24, p<.05$; and number ordering performance, $r(75)=.24, p<.05$.

[INSERT TABLE 2 HERE]

\section{Bootstrap correlations}

A Bootstrap procedure (using 10,000 samples) was also applied to assess the reliability of the relationship between the measures which had previously been observed as having a significant zero-order and/or partial correlation with maths, and maths achievement at each time point. This procedure allowed for a $95 \%$ confidence interval to be computed for the correlations between each measure and children's maths ability and if any measure was 
found to have a significant bootstrap correlation with maths, then it was considered to be robustly related to maths achievement. Figure 1 shows $95 \%$ bootstrap confidence intervals between the measures and maths achievement at the end of children's first year of school, whilst Figure 2 shows 95\% bootstrap confidence intervals between measures and maths achievement at the end of children's second year of school.

Figure 1 shows that the measures which had previously shown significant zero-order and/or partial correlations with maths at the end of children's first year of school also showed significant zero-order bootstrap correlations with maths. Figure 2 shows that order working memory accuracy $[r=.17,95 \% \mathrm{CI}(-.11, .41)]$ was the only measure that was not robustly related to maths at the longitudinal level, of all the measures that had previously been related to maths at the end of children's second year of school$^{3}$.

[INSERT FIGURE 1 HERE]

[INSERT FIGURE 2 HERE]

\section{Regression modelling}

The regression analyses regarding the relationship between the predictor variables and maths performance at each time point followed a similar procedure to that of Szücs, Devine, Soltesz, Nobes and Gabriel (2014). For each regression model, the variables that had a significant bootstrap correlation with maths were entered first. Non-significant predictors of

\footnotetext{
${ }^{3}$ Although in our main analyses we considered different types of formal maths skills together, the standardized tests that we used included several different types of problems (see Methods section). We present zero-order correlations between the measures that were robustly related to maths at each time point and the different components of the formal maths tasks (see Supplementary Tables 1 and 2). Typically, the best predictors of maths at each time point (in particular, the counting task and the daily events task) were significantly related to all aspects of maths. Interestingly, symbolic number ordering was also related to all aspects of maths at T1 and T2, although it was not included in the final regression models (see below), which suggests that its effect on maths was mediated by other tasks.
} 
maths in each model were then removed and each predictor, which had a significant partial correlation with maths but not a significant bootstrap correlation, was entered into the model one by one to examine whether they became significant. Then, the four covariates (age, deprivation scores, vocabulary and block design) were entered into the model, to examine whether they changed significant predictors and improved fit. At each time-point, the model that explained the greatest proportion of variance, with only significant predictors in the model, was selected.

Table 3 shows the initial and final models for measures that predicted maths at the end of children's first year of school. The initial model consisted of OPQ scores, order WM, daily events, number ordering, counting and number comparison accuracy. This model explained $37 \%$ of the variance in maths scores, however, this model contained a number of non-significant predictors of maths (order WM; $\beta=-.07, n . s$; number ordering; $\beta=.12, n . s$; number comparison; $\beta=-.03, n . s)$. These measures were removed and only the significant predictors (OPQ scores, daily events and counting accuracy) were entered into the next model. When adding them to the model one by one, none of the remaining predictors explained significant additional variance in maths performance. Thus, this was accepted as the final model (see Table 3).

[INSERT TABLE 3 HERE]

Table 4 shows the initial and final models for the measures that significantly predicted maths at the end of children's second year of school. The initial model consisted of OPQ scores, daily events, number ordering, counting, non-symbolic addition and number comparison accuracy. This initial model explained $30 \%$ of the variance in children's maths scores at the end of their second year of school. The non-significant predictors (number ordering, counting and number comparison) were removed and the next model contained 
OPQ scores, daily events and non-symbolic addition accuracy, which explained $27 \%$ of the variance in maths performance. The two intelligence measures and deprivation scores did not explain significant additional variance in maths performance, although age was a significant factor when included in the model containing OPQ scores, daily events and non-symbolic addition accuracy, with this model explaining $30 \%$ of the variance in children's maths performance at the end of their second year of school ${ }^{4}$.

\section{[INSERT TABLE 4 HERE]}

As a final step, we also checked if the longitudinal predictors of formal maths skills at the end of the second year of school also remained significant if the effect of formal maths skills at the end of the first school year were taken into account. We did this by adding formal maths skills at $\mathrm{T} 1$ as a predictor to the final regression model presented in Table 4 . This analysis addressed the question of whether these longitudinal predictors of maths also predicted growth in maths skills during the second year of school. The model is presented in Table 5. This model explained $41 \%$ of the variance in $\mathrm{T} 2$ formal maths skills with formal maths skills at T1, the order processing questionnaire and non-symbolic addition as

\footnotetext{
${ }^{4}$ Additional regression analyses were performed to investigate whether the results of the crosssectional and longitudinal regression models were the same for predicting only the arithmetic/calculation measures at $\mathrm{T} 1$ and $\mathrm{T} 2$. We conducted these analyses to demonstrate that ordering abilities were not simply related to a composite measure of maths achievement (which included various basic components of early maths ability, including some that were closely related to ordering). The same three predictors (OPQ, daily events and counting) that significantly predicted maths achievement at $\mathrm{T} 1$ also predicted arithmetic scores at $\mathrm{T} 1$ (these 3 predictors accounted for $31 \%$ of the variance in arithmetic scores. Three of the four significant longitudinal predictors of maths at T2 (OPQ, non-symbolic addition and daily events) also significantly predicted calculation scores at T2 (accounting for $19 \%$ of the variance in calculation scores). Age was not found to be a significant longitudinal predictor of calculation abilities. (Detailed results of these analyses can be found in Supplementary Tables 3 and 4).
} 
significant predictors. The effect of the daily event ordering task was no longer significant, and the effect of age was also reduced to a non-significant trend.

\section{[INSERT TABLE 5 HERE]}

\section{Discussion}

Children's ability to process both numerical order (counting, number ordering) and non-numerical order (OPQ, daily events and order working memory) at the start of their first school year were robustly related to their maths achievement at the end of their first year. These relationships were significant, even after controlling for age, deprivation scores and verbal and nonverbal intelligence. Multiple regression analyses revealed that, after controlling for the effect of counting ability (forwards and backwards), the order processing questionnaire and the daily events task still remained significant predictors of maths ability. The longitudinal analysis (i.e., predicting maths performance at the end of the second school year) showed that children's numerical ordering ability (counting forwards and backwards and symbolic number ordering) at the start of formal education was robustly related to their maths achievement at the end of their second year of school. Scores on the OPQ and daily events task accuracy were also robustly related to maths at the longitudinal level. The regression analyses revealed that early non-numerical ordering abilities (OPQ scores and daily events task accuracy) were significant predictors of children's maths achievement more than 1 year later even when the significant effects of counting ability, and non-symbolic addition were controlled. When the effect of $\mathrm{T} 1$ formal maths skills was controlled, only the OPQ and the non-symbolic addition task explained additional variance in T2 formal maths skills, whereas the effect of the daily events task was no longer significant. This suggests that the effect of the daily events task was the strongest during the first school year, and it related to maths abilities in the second year of school via its links with early formal maths skills. By 
contrast, everyday order processing abilities remained significantly related to formal maths skills throughout the first two years of school.

These results strongly support the notion that ordinality is important to the development of early maths skills (e.g., Attout \& Majerus, 2015; Attout, Noël \& Majerus, 2014; Lyons et al., 2014). Our detailed analyses of the components of the formal maths tests also showed that ordinality was important to all aspects of maths, including counting, calculation, and the understanding of number facts and measures. Our results also extend previous findings by showing that, even at the very earliest stages of formal schooling, children's domain-general ability to process order, as demonstrated in familiar everyday tasks and to a lesser extent, their ability to order daily events, plays an important role in the successful development of more mature maths skills. This extends work with adults (Morsanyi et al., 2017; Sasanguie et al., 2017; Vos et al., 2017) that showed strong relationships between non-numerical ordering tasks and mathematics abilities. The domaingeneral ability to use order information measured by the daily events task must be based on long-term memory representations of familiar sequences, and our findings indicate that it is distinct from the ability to process ordinal information held in short-term memory. Indeed, while we replicated Attout et al.'s (2014) findings of a concurrent relation between nonnumerical order WM and children's maths skills, performance on the OPQ and the daily events task were in fact better predictors of maths skills both concurrently and longitudinally.

Our results are novel in suggesting that there are two distinct domain-general ordering abilities that support maths development. Attout et al. (2014) show that the ability to hold ordered unfamiliar sequences in working memory is important, and make a strong case for why such an ability may be crucial for calculation abilities. Additionally, our results indicate that representing and processing familiar ordered sequences in long-term memory may be fundamental for the emergence of very early maths skills, when children are learning to 
represent and use numbers as an intrinsically ordinal sequence. The idea that such domaingeneral abilities underpin early maths skills is consistent with Rubinsten and Sury's (2011) claim that processing order information forms part of the cognitive foundations of mathematics.

Such a domain-general ability is likely to be in operation well before children learn mathematics, and indeed a considerable body of research indicates that children rapidly acquire representations of repeated event sequences over multiple time scales during the preschool years (Fivush \& Hammond, 1990; Nelson 1986, 1998). Acquiring and using ordered representations of repeated events forms a crucial part of children's learning about the world, and indeed has been argued to be foundational in cognitive development (Nelson, 1998). Our findings provide the first evidence that suggests that the same processes also support emerging maths abilities.

One important and unresolved issue, though, is whether there is a domain-general representational format for representing ordered information in long-term memory, and specifically whether such representations are spatial in nature. Our data do not allow us to answer this question, but we note that Friedman $(1977,1990)$ has argued that 4- to 5-yearolds have spatialized representations of familiar events (and, indeed, our daily event ordering task and our number ordering task required children to understand the mapping of temporal order to spatial order; though see Tillman, Tulagan, \& Barner, 2015, for evidence that 4-yearolds do not do this mapping spontaneously). Friedman and Brudos (1988) claimed that 4year-olds use a common representational system for coding both spatial and temporal order information, raising the possibility that the ability to represent items in this way is then utilized in the context of mathematics as well. Such an idea is broadly consistent with other claims regarding the way temporal order and numbers are represented (e.g., see Bonato, Zorzi, \& Umiltà, 2012, for review of research on the "mental time line" and "mental number 
line"). We note that Berteletti, Lucangeli, and Zorzi (2012) have made what could be interpreted as a contrasting claim, namely that children's conception of numerical order develops first and is then generalized to other non-numerical sequences. It is important to point out that the non-numerical sequences that they studied are those acquired later than the number sequence during formal education (the alphabet and months of the year), rather than familiar event sequences which are acquired very early in development. Moreover, the issue that Berteletti et al. are concerned with is whether the items in sequences in question are spaced linearly (by contrast to log spacing), rather than the more basic issue of whether they share a spatialized representational format. We note that children's performance on our number line task did not relate to performance either on the daily event task or on the OPQ, nor even on the number ordering task, suggesting that the precision of children's placing of numbers on a line measures something different to the ability to represent and process either numerical or non-numerical ordinal information.

Despite focused research on this issue, there is much that is not yet known about the commonalities between temporal, numerical, and spatial representation; we would suggest that our findings provide new impetus for considering such commonalities, particularly those between time (understood here as event order) and number, and how such commonalities may play a role in the acquisition of maths skills.

Another important contribution of the current work is that it provided the first evidence for a link between parentally-reported everyday ordering abilities and formal maths skills. Whereas clinical observations of individuals with developmental dyscalculia have described everyday order processing difficulties, this study was the first to show that this link is also present in the case of a sample of young, typically developing children. Indeed, the OPQ longitudinally predicted growth in formal maths skills during the second year of school. This finding could have great practical importance, as it offers the possibility to screen 
children for vulnerability to develop mathematics difficulties even before they start their formal education. Indeed, our questionnaire was designed for 4-year-old children; in many countries, this would be 2-3 years before the children start their formal education in maths. The questionnaire that we developed to measure children's everyday order processing abilities had good psychometric properties, and it only took a few minutes to complete, which makes it very convenient to use. Nevertheless, future work could further improve the psychometric properties and the predictive value of this questionnaire.

Our study examined a number of other predictors of maths skills used in previous studies. As we have pointed out, we replicated Attout et al.'s (2014) finding that order WM was related to maths skills in the first year of school, but in our sample, order working memory at the start of formal schooling did not longitudinally predict maths performance at the end of the second year of schooling. Regarding other predictors of maths performance, Lyons et al. (2014) found that number comparison and number line performance were the best predictors of maths performance in the first school year. We also found a robust relationship between number comparison performance and maths skills both at the crosssectional and longitudinal levels, which is also in line with several other studies that showed a strong relationship between number comparison and maths skills at the start of formal education (e.g., Attout et al., 2014; Holloway \& Ansari, 2009; Mundy \& Gilmore, 2009; Rousselle \& Noël 2007). Given the well-established link between this task and maths ability, and the fact that it involves symbolic number processing, it is striking, though, that number comparison did not explain additional variance in maths skills, once the effect of counting skills and everyday ordering abilities were controlled.

Regarding number line performance, several studies found a reliable relationship between this task and maths achievement in children from as young as 3 years old (e.g., Berteletti et al., 2010; Booth \& Siegler; 2006, 2008; Link, Huber, Nuerk \& Moeller, 2014; 
Siegler \& Booth, 2004). Studies typically use a paper-and-pencil version of this task, and it is possible that the link between maths skills and performance on the number line task would have been stronger had we used the typical presentation format. Nevertheless, the task showed good reliability, and children's estimations were not very far from the correct positions of target numbers. Performance on this task was also related to children's block design scores, which supports the validity of the tasks. There was also a non-significant trend $(p=.118)$ toward a relationship between number line performance and formal maths skills at T2.

Number ordering performance was significantly related to math abilities both in year 1 and year 2. Nevertheless, surprisingly, non-numerical ordering tasks were more strongly related to maths abilities than number ordering. This raises the question of whether our version of the task was ideally suited to measure number ordering skills. As we noted earlier, other researchers used computer-based verification tasks to measure number ordering skills in young children (e.g., Lyons et al., 2014) that were analogous to our daily events task, albeit involving numbers. However, in a pilot test, our participants found this version of the task too challenging, possibly because they were younger than the participants in all the other studies. Some researchers (e.g., Attout \& Majerus, 2015; Attout, Noël \& Majerus, 2014; Vogel, Remark \& Ansari, 2015) presented children with dyads of numbers rather than triads in their number ordering task. The dyad version was successfully performed by children as young as 5-6 years old (Attout et al., 2014). However, an issue with this version of the task is that Vogel et al. (2015) reported no reverse distance effects on the task, which have been consistently found by researchers who used number triads in their ordering task. Thus, it is possible that the two versions of the number ordering task (i.e., using dyads vs. triads) do not rely on exactly the same cognitive processes. In particular, it is less certain that participants 
must rely on order information per se in the dyad task than in the triad task. For these reasons, we employed a production version of the number ordering task.

We believe that this task was appropriate for our sample, given that we found stronger correlations between number ordering and maths skills than other researchers who looked at this relationship in the case of young children (e.g. Attout et al., 2014; Lyons et al., 2014; Vogel, Remark \& Ansari, 2014). Indeed, the typical finding in the case of young children is a weak/non-significant relationship ${ }^{5}$. By contrast, we found that number ordering was significantly related to all aspects of maths both at T1 and T2. Furthermore, we found a moderate relationship between the daily events task and the number ordering task, suggesting that both tasks were assessing some of the same skills. Regarding the predictive value of production vs. verification tasks, whilst we did not use the verification version of the number ordering task, our number comparison task was a verification task. Although children performed better on that task than on the daily events task (i.e., a verification task that measured ordering ability), performance on the number comparison task was less strongly related to maths than the daily events task at both $\mathrm{T} 1$ and $\mathrm{T} 2$.

There is evidence that, as children get older, number ordering skills become increasingly strongly related to maths abilities (see Lyons et al., 2014). Regarding nonnumerical ordering skills, the developmental pattern of their links with math abilities have not been investigated so far. Some recent studies (e.g., Morsanyi et al., 2017, Sasanguie et al., 2017, Vos et al., 2017) have demonstrated that non-numerical ordering skills remain strongly related to arithmetic skills even in the case of adults, although these links are not quite as

\footnotetext{
${ }^{5}$ The sample in Vogel et al. (2015) consisted of children in $1^{\text {st }}$ grade in Canada, who were aged between 6 and 7 years old. The authors failed to find a relationship between the size of the numerical distance effect or mean reaction times for the order judgment task and maths. In Attout et al. (2014), the children were between 5-6 at T1; 6-7 at T2 and 7-8 at T3. There were significant associations between numerical ordering and maths at T2 and T3, but not at T1. Lyons et al. (2014) found that number ordering ability was not a significant predictor of math in grades 1 and 2 (between 6-8 years old) but was a significant predictor of maths from grade 3 onwards (from age 9).
} 
strong as the relations between numerical ordering skills and maths. Thus, it is plausible to assume that at some point in development (most likely, during the first years of school) number ordering skills become more strongly related to maths skills than non-numerical ordering. Nevertheless, this question requires further investigation.

Non-symbolic addition performance was a significant predictor of children's later maths achievement, and growth in formal maths skills during the second year of school, although it was not related to maths performance at the end of the first school year. The task was designed in such a way that children could not perform above chance if they only relied on simple perceptual strategies (see Gilmore et al., 2010; Rousselle \& Noel, 2007; Soltesz, Szücs \& Szücs, 2010). Unsurprisingly, young children found this task difficult. Whereas the finding that performance on this task predicted maths performance is in line with studies that found a link between non-symbolic estimation skills and mathematics performance (see Chen \& Li, 2014 for a meta-analysis), it is important to note that the non-symbolic addition task has further cognitive requirements, including memory, spatial attention and inhibition, which are also important for maths development.

Indeed, one limitation of the current study is that it did not consider some domaingeneral factors that are likely to play a role in numerical development. Although IQ and order working memory were measured in the current study, other general cognitive skills were not considered. There is much evidence to suggest that other aspects of working memory processes (Passolunghi, Cargnetti \& Pastore, 2014; Passolunghi \& Shadee, 2007; Szücs, Devine, Soltesz, Nobes \& Gabriel, 2013; Van der Ven, Van der Maas, Straatemeier \& Jansen, 2013) and executive functions (Gilmore et al., 2013; Passolunghi \& Siegel, 2001; Soltesz, Szücs \& Szücs, 2010; Szücs, Devine, Soltesz, Nobes \& Gabriel, 2013) are related to maths. In particular, it would be interesting to investigate verbal and spatial working memory and inhibition skills together with the ordering tasks, as these skills might play a role in 
ordering performance (e.g., van Dijck, Abrahamse, Majerus \& Fias, 2013; van Dijck \& Fias, 2011; Morsanyi et al., 2017).

Another limitation that could be noted is that formal maths skills were not assessed at the start of the first school year. Indeed, although we used a broad range of tasks to measure basic maths abilities (including non-symbolic measures, counting skills, and measures that required the knowledge of symbolic numbers, such as the number line task, and the number ordering task), it is possible that children had already possessed some of the formal maths skills (e.g., addition and subtraction) that were assessed at the end of the first school year. The majority of the children would have attended state-funded nurseries the year before their first year, i.e., at aged 3 to 4 years, due to universal free provision in the UK. Nurseries do not teach formal maths skills such as addition and subtraction, but perhaps some children had been taught these skills at home (although we note that at the start of the study the children were still very young with a mean age of less than 5 years). Thus, although our findings demonstrated that early, non-numerical ordering skills were strongly related to formal maths skills at the end of the first school year, it is unclear if early ordering abilities predicted growth in formal math abilities during the first school year. This question might be explored in future studies.

Finally, we have already discussed the possibility of using everyday ordering abilities as early indicators of potential vulnerability to maths difficulties in young children. Another possible future direction is to develop non-numerical training exercises that could be used to help young children to improve their ordering abilities. One interesting question is whether the effects of training in non-numerical ordering might generalize to number ordering skills, and numerical skills in general. In fact, there is a possibility that ordering skills might play an important role in the development of other academic skills as well, as Perez, Majerus and Poncelet (2012) found that order WM capacity longitudinally predicted reading development 
in the case of young children. The same authors (Perez, Majerus \& Poncelet, 2013) also reported that adults with dyslexia displayed a deficit in order WM. It is possible that the link between domain-general order processing and other academic skills is specific to short-term memory mechanisms, but our findings suggest that it might be useful to examine whether such a link also extends to the sort of ordering processing skills measured in our study.

In conclusion, the current study has shown that children's ability to process order, at the earliest stage of formal schooling, is an important predictor of maths achievement concurrently and 1 year later. In particular, it seems that non-numerical ordering ability (for familiar tasks and daily events) is a stronger predictor of children's maths ability than numerical order at the early stages of education. Although on the basis of the current findings it is not possible to establish if early non-numerical ordering abilities predict growth in formal maths skills during the first school year, such evidence was found in the second year of school, at least in the case of the parental report of children's ordering skills. General ordering ability may be a suitable target for intervention for young children, and measuring ordering ability could potentially be used to identify children who are at risk of developing maths difficulties, even before they start formal education. 


\section{References}

Attout, L. \& Majerus, S. (2014). Working memory deficits in developmental dyscalculia: The importance of serial order. Child Neuropsychology, 21, 432-450.

Attout, L., Noël, M. P. \& Majerus, S. (2015). The relationship between working memory for serial order and numerical development: A longitudinal study. Developmental Psychology, 50, 1667-1679.

Aagten-Murphy, D., Attucci, C., Daniel, N., Klaric, E., Burr, D., \& Pellicano, E. (2015). Numerical estimation in children with autism. Autism Research, 8, 668-681.

Berteletti, I., Lucangeli, D., Piazza, M., Dehaene, S. \& Zorzi, M. (2010). Numerical estimation in preschoolers. Developmental Psychology, 46, 545-551.

Bonato, M., Zorzi, M., \& Umiltà, C. (2012). When time is space: evidence for a mental time line. Neuroscience \& Biobehavioral Reviews, 36, 2257-2273.

Booth, J. L., \& Siegler, R. S. (2008). Numerical magnitude representations influence arithmetic learning. Child Development, 79, 1016-1031.

Booth, J. L., \& Siegler, R. S. (2006). Developmental and individual differences in pure numerical estimation. Developmental Psychology, 42, 189. 
Butterworth B. (2005) Developmental Dyscalculia. In: Campbell, J. D. (Eds). The Handbook of Mathematical Cognition. New York: Psychology Press. 455-469.

Chen, Q. \& Li, J. (2014). Association between individual differences in non-symbolic number acuity and math performance: A meta-analysis. Acta Psychologica, 148, 163172.

Cohen, D. J. \& Blanc-Goldhammer, D. (2011). Numerical bias in bounded and unbounded number line tasks. Psychonomic Bulletin \& Review, 18, 331-338.

Dehaene, S., Dupoux, E. \& Mehler, J. (1990). Is numerical comparison digital? Analogical and symbolic effects in two-digit number comparison. Journal of Experimental Psychology: Human Perception and Performance, 16, 626-641.

De Smedt, B., Noël, M. P., Gilmore, C., \& Ansari, D. (2013). How do symbolic and nonsymbolic numerical magnitude processing skills relate to individual differences in children's mathematical skills? A review of evidence from brain and behavior. Trends in Neuroscience and Education, 2, 48-55.

Eurydice at NFER - National Foundation for Educational Research: Compulsory age of starting school in European countries (2012). Retrieved 10 ${ }^{\text {th }}$ August 2016 from https://www.nfer.ac.uk/nfer/eurydice/publications/compulsory-age-of-starting$\underline{\text { school.cfm }}$ 
Fivush, R., \& Hammond, N. (1990). Autobiographical memory across the preschool years: toward reconceptualising childhood amnesia. In R. Fivush and J. Hudson (Eds.), Knowing and Remembering in Young Children.New York: Cambridge University Press.

Friedman, W. J. (1990). Children's representations of the pattern of daily activities. Child Development, 61, 1399-1412.

Friedman, W. J. (1977). The development of children's knowledge of cyclic aspects of time. Child Development. 48, 1593-1599.

Friedman, W. J., \& Brudos, S. L. (1988). On routes and routines: The early development of spatial and temporal representations. Cognitive Development, 3(2), 167-182.

Gilmore, C., Attridge, N., Clayton, S., Cragg, L., Johnson, S., Marlow, N., ... \& Inglis, M. (2013). Individual differences in inhibitory control, not non-verbal number acuity, correlate with mathematics achievement. PLoS One, 8, e67374.

Gilmore, C., Attridge, N., De Smedt, B., \& Inglis, M. (2014). Measuring the approximate number system in children: exploring the relationships among different tasks. Learning and Individual Differences, 29, 50-58.

Gilmore, C. K., McCarthy, S. E., \& Spelke, E. S. (2010). Non-symbolic arithmetic abilities and mathematics achievement in the first year of formal schooling. Cognition, 115, 394-406. 
Ginsburg, H. P., \& Baroody, A. J. (2003). Test of Early Mathematics Ability, Third Edition. Austin, TX: Pro- Ed

Goffin, C., \& Ansari, D. (2016). Beyond magnitude: Judging ordinality of symbolic number is unrelated to magnitude comparison and independently relates to individual differences in arithmetic. Cognition, 150, 68-76.

Halberda, J., Mazzocco, M. M. \& Feigenson, L. (2008). Individual differences in nonverbal number acuity predict maths achievement. Nature, 455, 665-668.

Hannula, M. M., \& Lehtinen, E. (2005). Spontaneous focusing on numerosity and mathematical skills of young children. Learning and Instruction, 15, 237-256.

Holloway, I. D. \& Ansari, D. (2009). Mapping numerical magnitudes onto symbols: the distance effect and children's mathematical competence. Journal of Experimental Child Psychology, 103, 17-29.

Inglis, M., \& Gilmore, C. (2014). Indexing the approximate number system. Acta Psychologica, 145, 147-155.

Iuculano, T., Tang, J., Hall, C. W., \& Butterworth, B. (2008). Core information processing deficits in developmental dyscalculia and low numeracy. Developmental Science, 11, 669-680. 
Kaufmann, L., Vogel, S. E., Starke, M., Kremser, C., \& Schocke, M. (2009). Numerical and non-numerical ordinality processing in children with and without developmental dyscalculia: Evidence from fMRI. Cognitive Development, 24, 486-494.

Laski, E. V., \& Siegler, R. S. (2007). Is 27 a big number? Correlational and causal connections among numerical categorization, number line estimation, and numerical magnitude comparison. Child Development, 78(6), 1723-1743.

Link, T., Huber, S., Nuerk, H. C., \& Moeller, K. (2014). Unbounding the mental number line — new evidence on children's spatial representation of numbers. Frontiers in Psychology, 4, 1-11.

Lyons, I. M., Vogel, S. E., \& Ansari, D. (2016). On the ordinality of numbers: A review of neural and behavioral studies. Progress in Brain Research, 227, 187-221.

Lyons, I. M. \& Beilock, S. L. (2011). Numerical ordering ability mediates the relation between number-sense and arithmetic competence. Cognition, 121, 256-261.

Lyons, I. M., Price, G. R., Vaessen, A., Blomert, L. \& Ansari, D. (2014). Numerical predictors of arithmetic success in grades 1-6. Developmental Science, 1-13.

Majerus, S., Poncelet, M., Greffe, C., \& Van der Linden, M. (2006). Relations between vocabulary development and verbal short-term memory: The relative importance of short-term memory for serial order and item information. Journal of Experimental Child Psychology, 93, 95-119. 
Morsanyi, K., Devine, A., Nobes, A. \& Szücs, D. (2013). The link between logic, mathematics and imagination. Evidence from children with developmental dyscalculia and mathematically gifted children. Developmental Science, 16, 542-553.

Morsanyi, K., O’Mahony, E., \& McCormack, T. (2017). Number comparison and number ordering as predictors of arithmetic performance in adults: Exploring the link between the two skills, and investigating the question of domain-specificity. The Quarterly Journal of Experimental Psychology (in press) DOI: $10.1080 / 17470218.2016 .1246577$

Mundy, E., \& Gilmore, C. K. (2009). Children's mapping between symbolic and nonsymbolic representations of number. Journal of Experimental Child Psychology, 103, 490-502.

National Center for Learning Disabilities: Understanding Dyscalculia (2007). Retrieved $17^{\text {th }}$ October 2017 from http://www.ldonline.org/article/13709/

Nelson, K. (1998). Language in cognitive development: The emergence of the mediated mind. Cambridge University Press.

Nelson, K. (1986). Event knowledge: Structure and function in development. Hillsdale, NJ: Erlbaum.

Nieder, A., \& Dehaene, S. (2009). Representation of number in the brain. Annual Review of Neuroscience, 32, 185-208. 
Northern Ireland Statistics and Research Agency (2010). Northern Ireland Multiple Deprivation Measure 2010: Blueprint Document. February 2010. Retrieved 23 ${ }^{\text {rd }}$ June, 2014 , from http://www.nisra.gov.uk/deprivation/archive/Updateof2005Measures/NIMDM_2010_ Blueprint_Document.pdf

Passolunghi, M. C., Cargnelutti, E. \& Pastore, M. (2014). The contribution of general cognitive abilities and approximate number system to early mathematics. British Journal of Educational Psychology, 84, 631-649.

Passolunghi, M. C., \& Siegel, L. S. (2001). Short-term memory, working memory, and inhibitory control in children with difficulties in arithmetic problem solving. Journal of Experimental Child Psychology, 80, 44-57.

Passolunghi, M. C., Vercelloni, B. \& Schadee, H. (2007). The precursors of mathematics learning: Working memory, phonological ability and numerical competence. Cognitive Development, 22(2), 165-184.

Perez, T. M., Majerus, S., \& Poncelet, M. (2013). Impaired short-term memory for order in adults with dyslexia. Research in Developmental Disabilities, 34, 2211-2223.

Perez, T. M., Majerus, S., \& Poncelet, M. (2012). The contribution of short-term memory for serial order to early reading acquisition: Evidence from a longitudinal study. Journal of Experimental Child Psychology, 111, 708-723. 
Piazza, M., Facoetti, A., Trussardi, A. N., Berteletti, I., Conte, S., Lucangeli, D....\& Zorzi, M. (2010). Developmental trajectory of number acuity reveals a severe impairment in developmental dyscalculia. Cognition, 116, 33-41.

Price, G. R., Palmer, D., Battista, C., \& Ansari, D. (2012). Nonsymbolic numerical magnitude comparison: Reliability and validity of different task variants and outcome measures, and their relationship to arithmetic achievement in adults. Acta Psychologica, 140, 50-57.

Rousselle, L., \& Noël, M. P. (2007). Basic numerical skills in children with mathematics learning disabilities: A comparison of symbolic vs non-symbolic number magnitude processing. Cognition, 102, 361-395.

Rubinsten, O., \& Sury, D. (2011). Processing ordinality and quantity: the case of developmental dyscalculia. PLoS One, 6, e24079.

Sasanguie, D., Defever, E., Maertens, B., \& Reynvoet, B. (2014). The approximate number system is not predictive for symbolic number processing in kindergarteners. The Quarterly Journal of Experimental Psychology, 67, 271-280.

Sasanguie, D., De Smedt, B., \& Reynvoet, B. (2017). Evidence for distinct magnitude systems for symbolic and non-symbolic number. Psychological Research, 81, 231242. 
Sattler, J. M., \& Dumont, R. (2004). Assessment of children: WISC-IV and WPPSI-III supplement. San Diego: Jerome M. Sattler, Publisher.

Schneider, M., Beeres, K., Coban, L., Merz, S., Schmidt, S., Stricker, J. \& De Smedt, B. (2016). Associations of non-symbolic and symbolic numerical magnitude processing with mathematical competence: a meta-analysis. Developmental Science. Ahead-ofprint

Siegler, R. S., \& Booth, J. L. (2004). Development of numerical estimation in young children. Child development, 75, 428-444.

Siegler, R. S. \& Opfer, J. E. (2003). The development of numerical estimation evidence for multiple representations of numerical quantity. Psychological Science, 14, 237-250.

Soltész, F., Szűcs, D. \& Szűcs, L. (2010). Relationships between magnitude representation, counting and memory in 4-to 7-year-old children: A developmental study. Behavioral and Brain Functions, 6, 1-14.

Szűcs, D., Devine, A., Soltesz, F., Nobes, A., \& Gabriel, F. (2013). Developmental dyscalculia is related to visuo-spatial memory and inhibition impairment. Cortex, 49 , 2674-2688.

Tillman, K., Tulagan, N., \& Barner, D. (2015). Building the mental timeline: Spatial representations of time in preschoolers. Proc. CogSci. 
Van Der Ven, S. H., Van Der Maas, H. L., Straatemeier, M., \& Jansen, B. R. (2013). Visuospatial working memory and mathematical ability at different ages throughout primary school. Learning and Individual Differences, 27, 182-192.

van Dijck, J. P., Abrahamse, E. L., Majerus, S., \& Fias, W. (2013). Spatial attention interacts with serial-order retrieval from verbal working memory. Psychological Science, 24, 1854-1859.

van Dijck, J. P., \& Fias, W. (2011). A working memory account for spatial-numerical associations. Cognition, 119, 114-119.

Van Heuven, W. J., Mandera, P., Keuleers, E., \& Brysbaert, M. (2014). SUBTLEX-UK: A new and improved word frequency database for British English. The Quarterly Journal of Experimental Psychology, 67, 1176-1190.

Vogel, S. E., Remark, A., \& Ansari, D. (2015). Differential processing of symbolic numerical magnitude and order in first-grade children. Journal of Experimental Child Psychology, 129, 26-39.

von Aster, M. G., \& Shalev, R. S. (2007). Number development and developmental dyscalculia. Developmental Medicine and Child Neurology, 49, 868-873.

Vos, H., Sasanguie, D., Gevers, W., \& Reynvoet, B. (2017). The role of general and numberspecific order processing in adults' arithmetic performance. Journal of Cognitive Psychology, 1-14. 
Walsh, V. (2003). A theory of magnitude: common cortical metrics of time, space and quantity. Trends in Cognitive Sciences, 7, 483-488.

Wechsler, D. (2003) Wechsler Preschool and Primary Scale of Intelligence - Third UK Edition (WPPSI-III). Oxford, England. Psychological Corp.

Williams, J. (2005). Mathematics assessment for learning and teaching. London: Hodder Education. 


\section{Appendix}

\section{Parental Order-Processing Questionnaire}

Please circle the number which you feel best applies to your child for each question (1=very much disagree; 7=very much agree)

My son/daughter:

Is easily confused by changes in routine 1----2----3----4-----5----6----7

Understands how the seasons of the year follow each other (e.g. that autumn $1----2----3----4----5----6----7$ always comes after summer)

Can easily recall the order in which past 1----2-----3----4-----5----6----7 events happened

Is able to plan a sequence of activities 1----2----3----4-----5----6----7 independently 
Finds it difficult to learn new activities

which involve a sequence of actions

which have to be performed in a

1----2----3----4-----5----6----7

particular order (e.g., putting together

the parts of a toy in the right order).

Would be able to recall the order of

1----2----3----4-----5----6----7

typical daily events.

Understands that some things always

have to be done in a particular order

1----2----3----4-----5----6----7

(e.g. putting on a school shirt before

putting on a tie)

Finds it difficult to understand how the

days of the week follow each other (e.g.

1----2----3----4-----5----6----7

knowing that Wednesday comes after

Tuesday) 
Table 1. Descriptive statistics for all measures

\begin{tabular}{|c|c|c|c|}
\hline Measure & Minimum & Maximum & Mean $(S D)$ \\
\hline Vocabulary (scaled score) & 4 & 17 & $8.52(2.10)$ \\
\hline Block Design (scaled score) & 4 & 16 & $10.12(3.15)$ \\
\hline Order Processing Questionnaire & 21 & 56 & $44.02(7.69)$ \\
\hline Order WM & 1 & 16 & $9.52(4.54)$ \\
\hline Daily Events Accuracy & .38 & 1 & $.65(.13)$ \\
\hline Symbolic number ordering & 0 & 1 & $.82(.30)$ \\
\hline Counting to 50 & 6 & 50 & $39(13.15)$ \\
\hline Counting forward and backward & 0 & 1 & $.76(.22)$ \\
\hline Non-symbolic addition & .30 & .88 & $.56(.11)$ \\
\hline Number Comparison Acc. & .40 & 1 & $.71(.19)$ \\
\hline Number Comparison RT (ms) & 778 & 6059 & $2404.04(1044.16)$ \\
\hline
\end{tabular}


Number Line task (Mean scaled error)

Baseline RT (ms)

Maths (Year 1)

Maths (Year 2)
.87

860

2284

$1435(283.71)$

1

28

$23.24(4.88)$

7

29

$21.74(4.71)$ 
Table 2. Zero-order correlations between all measures.
(1)
(2)
(3)
(4)
(5)
(6)
(7)
(8)
(9)
(10) (11) (12)
(13) (14)

\begin{tabular}{|c|c|c|c|c|c|c|c|c|c|c|c|c|c|}
\hline (1) Age & - & & & & & & & & & & & & \\
\hline (2) Vocabulary & .04 & - & & & & & & & & & & & \\
\hline (3) Block Design & .09 & .09 & - & & & & & & & & & & \\
\hline (4) Deprivation & .11 & $-.41 * * *$ & $-.22 *$ & - & & & & & & & & & \\
\hline (5) Order Processing Q. & .08 & .15 & .03 & -.09 & - & & & & & & & & \\
\hline (6) Order WM & .17 & $.22 *$ & $.30 * *$ & $-.22 *$ & .18 & - & & & & & & & \\
\hline (7) Daily Events & -.09 & $.38 * * *$ & $.29 * *$ & $-.27 * *$ & -.08 & $.44 * * *$ & - & & & & & & \\
\hline (8) Number Ordering & .14 & .19 & $.24 *$ & $-.23 *$ & $.26^{*}$ & $.41 * * *$ & $.24 *$ & - & & & & & \\
\hline (9) Counting & .09 & $.27 * *$ & .13 & -.10 & .15 & $.54 * * *$ & $.34 * *$ & $.36 * *$ & - & & & & \\
\hline (10) Non-Symbolic Add. & $-.23 *$ & $.24 *$ & .12 & -.19 & -.14 & .11 & $.22 *$ & .19 & .02 & - & & & \\
\hline (11) Number Comparison & .06 & .18 & .09 & $-.22 *$ & .20 & $.28 * *$ & $.34 * *$ & $.29 * *$ & $.29 * *$ & .15 & - & & \\
\hline (12) Number Line (Error) & $.21 *$ & -.02 & $-.26^{*}$ & .10 & .11 & -.05 & -.15 & -.05 & -.20 & -.14 & -.04 & - & \\
\hline (13) Maths (Year 1) & -.004 & $.32 * *$ & .16 & $-.26^{*}$ & $.30 * *$ & $.32 * *$ & $.46^{* * *}$ & $.40 * * *$ & $.54 * * *$ & .14 & $.21 *$ & .02 & - \\
\hline (14) Maths (Year 2) & .10 & $.37 * * *$ & $.29 * *$ & $-.29 * *$ & $.28^{*}$ & $.23 *$ & $.41 * * *$ & $.38^{* * *}$ & $.43 * *$ & $.30 * *$ & $.24 *$ & -.17 & $.69 * * *$ \\
\hline
\end{tabular}


Task Abbreviation: Add.: addition. Q: Questionnaire. WM: Working memory

$* p<.05, * * p<.01, * * * p<.001$ 
Table 3. Initial and final models predicting maths achievement at the end of children's first year of school.

\begin{tabular}{lllll}
\hline & & $\beta$ & $t$ & $p$ \\
\hline Initial model & Daily events & .39 & 3.90 & $<.001$ \\
& Counting & .33 & 3.09 & .003 \\
& Order Processing Questionnaire & .27 & 2.89 & .005 \\
& Symbolic number ordering & .12 & 1.25 & .214 \\
& Order WM & -.07 & -.65 & .520 \\
& Number comparison & -.03 & -.31 & .759 \\
\hline Final model & Daily events & .38 & 4.17 & $<.001$ \\
& Counting & .32 & 3.49 & .001 \\
& Order Processing Questionnaire & .28 & 3.23 & .002
\end{tabular}

Initial model: $R^{2}=.37, F(6,84)=9.33, p<.001$.

Final model: $R^{2}=.39, F(3,84)=18.39, p<.001$. 
Table 4. Initial and final regression models predicting maths achievement at the end of children's second year of school.

\begin{tabular}{llccc}
\hline & & $\beta$ & $t$ & $p$ \\
\hline Initial model & Order Processing Questionnaire & .28 & 2.77 & .007 \\
& Non-Symbolic addition & .26 & 2.60 & .011 \\
& Daily events & .25 & 2.38 & .020 \\
& Counting & .19 & 1.80 & .075 \\
& Symbolic Number Ordering & .11 & 1.07 & .289 \\
& Number Comparison & .04 & .35 & .728 \\
\hline Final model & Daily events & .35 & 3.67 & $<.001$ \\
& Order Processing Questionnaire & .32 & 3.36 & .001 \\
& Non-symbolic addition & .30 & 3.04 & .003 \\
& Age & .20 & 2.06 & .042 \\
& & & &
\end{tabular}

Initial model: $R^{2}=.30, F(6,81)=6.71, p<.001$.

Final model: $R^{2}=.30, F(4,81)=9.53, p<.001$. 
Table 5. Regression model predicting formal maths achievement at the end of children's second year of school taking into account the effect of formal maths achievement at the end of the first school year.

\begin{tabular}{llll}
\hline & $\beta$ & $t$ & $p$ \\
& & & \\
& & & \\
T1 maths & .41 & 3.92 & $<.001$ \\
Daily events & .16 & 1.62 & .109 \\
Order Processing Questionnaire & .19 & 2.03 & .045 \\
Non-symbolic addition & .26 & 2.93 & .004 \\
Age & .17 & 1.95 & .054 \\
\hline$R^{2}=41, F(5,81)=12.13, p<.001$ & & &
\end{tabular}




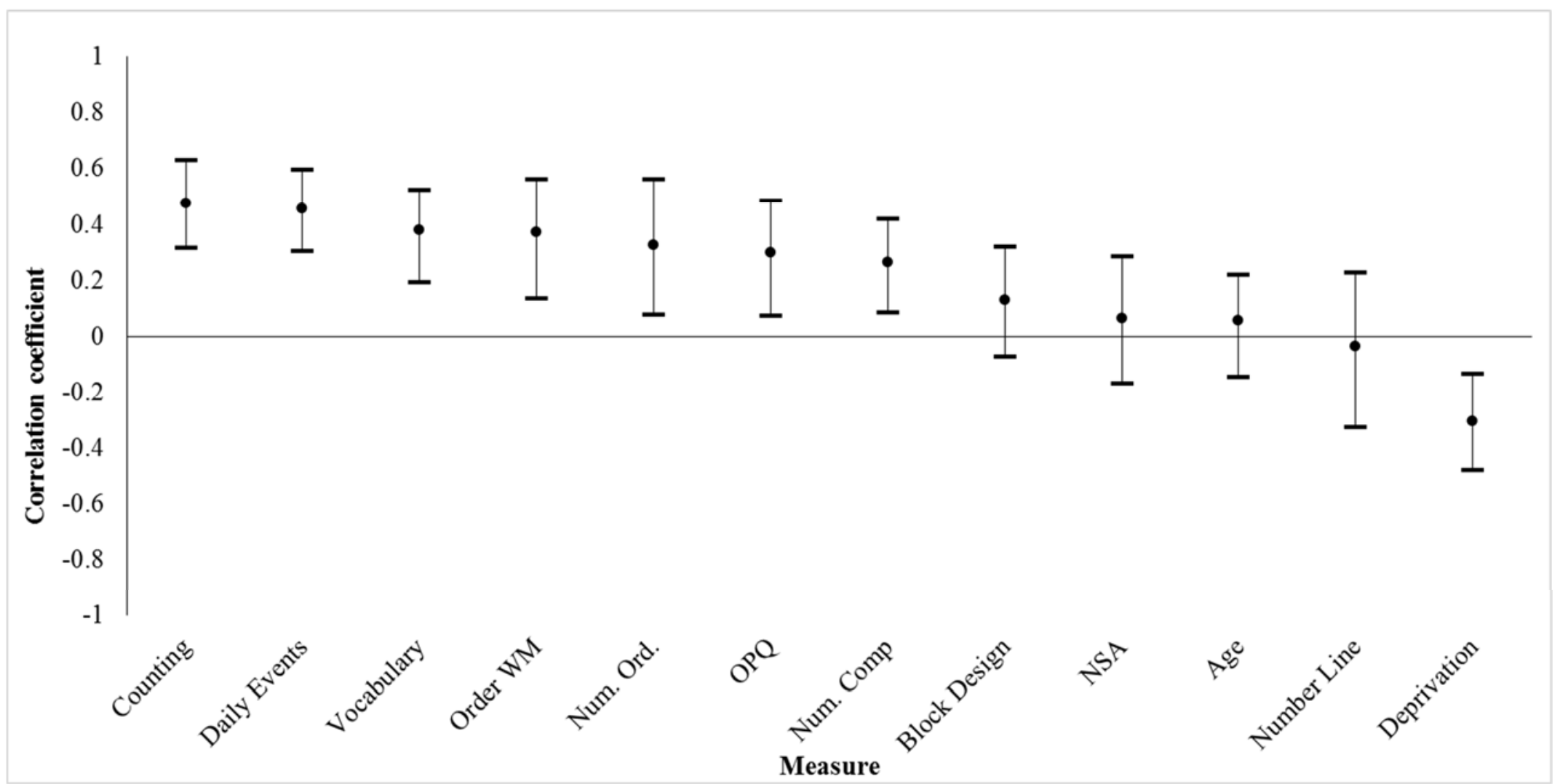

Figure 1. 95\% bootstrap confidence intervals for zero-order correlations between measures and maths achievement at the end of children's first year of school. Task Abbreviation: NSA: Non-symbolic addition. Num. Comp.: Number Comparison. Num. Ord.: Number Ordering. OPQ: parental order-processing questionnaire. WM: Working memory 


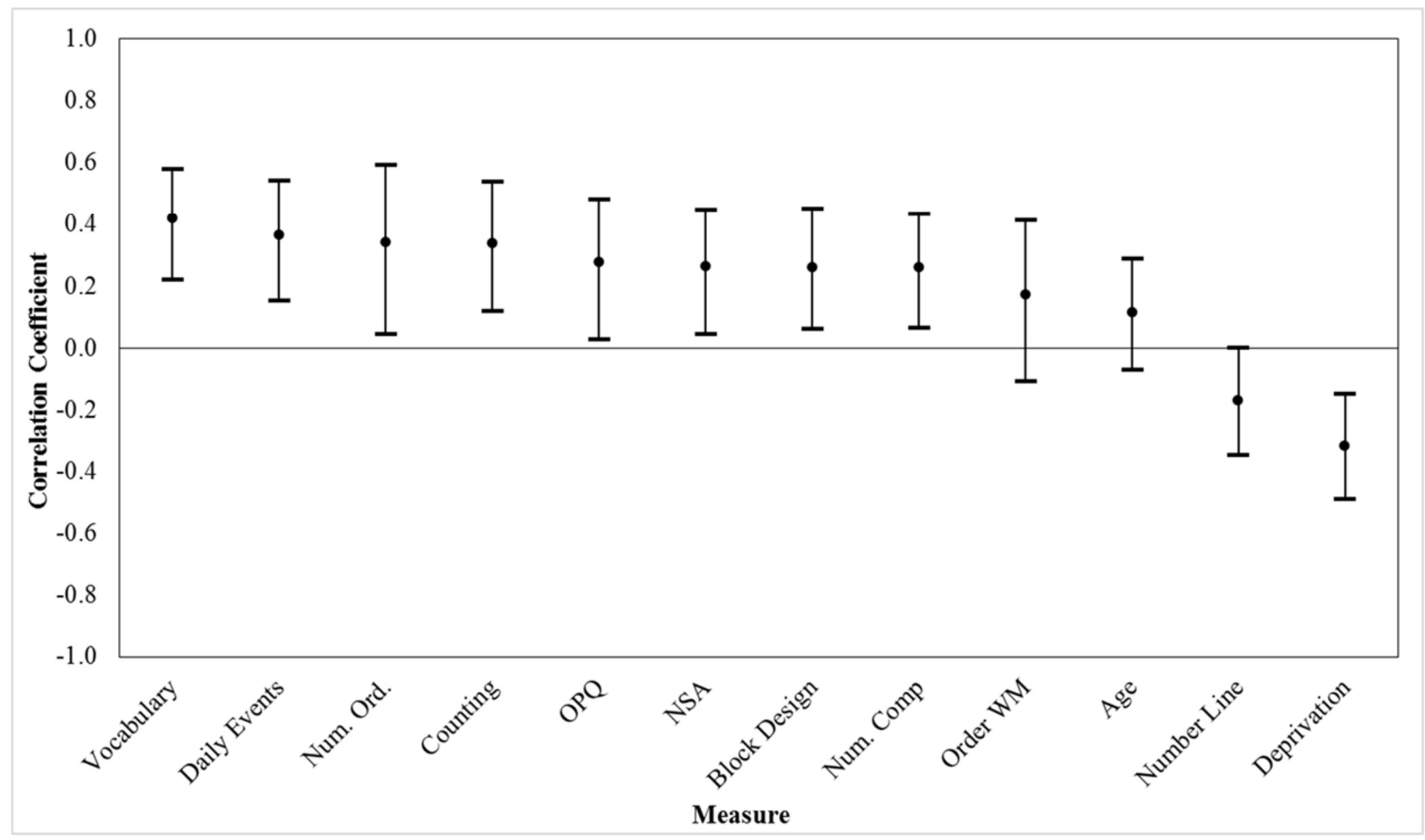

Figure 2. 95\% bootstrap confidence intervals for zero-order correlations between measures and maths achievement at the end of children's second year of school. Task Abbreviation: NLT: Number line task. NSA: Non-symbolic addition. Num. Comp.: Number Comparison. Num. Ord.: Number Ordering. OPQ: parental order-processing questionnaire. WM: Working memory. 